\title{
CONDICIONES DE VIDA EN ÁREAS DE ALTO REZAGO SOCIAL Y FACTORES SOCIODEMOGRÁFICOS DE LA POBREZA MULTIDIMENSIONAL EN BAJA CALIFORNIA
}

\author{
Living conditions in areas of high social \\ deprivation and socio-demographic factors of \\ multidimensional poverty in Baja California
}

Cuauhtémoc Calderón Villarreal ${ }^{1}$, Óscar Peláez Herreros ${ }^{2}$

Fecha de recepción: 08 de diciembre de 2016

Fecha de aceptación: 23 de diciembre de 2016

1- Nacionalidad: Mexicana. Grado: Doctor en economía. Especialización: Desarrollo económico y crecimiento. Adscripción: El Colegio de la Frontera Norte. Correo electrónico: calderon@colef.mx. SNI III. Profesor invitado de la Universidad Panamericana.

2- Nacionalidad: Española. Grado: Doctor en economía. Especialización: Economía regional. Adscripción: El Colegio de la Frontera Norte. Correo electrónico: opelaez@colef.mx 


\section{Resumen}

A partir de un censo aplicado en zonas de muy alto rezago social de los municipios de Mexicali, Tecate, Tijuana y Playas de Rosarito, se obtuvo información sobre las condiciones de vida de 39,418 residentes. El artículo presenta los resultados de ese censo en relación a las características de las viviendas y de los integrantes de los hogares, y clasifica a los encuestados según las categorías de la pobreza multidimensional. Posteriormente, se estima un modelo logit ordinal con el fin de analizar la relación entre condiciones sociodemográficas y pobreza, y definir el perfil más propenso a padecerla. Los resultados indican que ese perfil se corresponde con el de una joven, desempleada, indígena, con alguna discapacidad, nacida en el suroeste del país, que no ha vivido en Estados Unidos y que reside en un hogar numeroso, con pocos familiares empleados y jefatura femenina con bajo nivel de estudios, en Playas de Rosarito.

Palabras clave: pobreza multidimensional, modelo logit ordinal, Baja California.

\section{Abstract}

The information of this paper comes from a census that we apply in areas of high social deprivation in the municipalities of Mexicali, Tecate, Tijuana and Playas de Rosarito, obtaining data on living conditions of 39,418 residents. The paper describes the results of the census in relation to the characteristics of dwellings and household members, and classifies the population according to the categories of multidimensional poverty. Later, an ordinal logit model was used to estimate the relationship between socio-demographic conditions and poverty, and to define the profile most likely to suffer from poverty. The results indicate that the most prone profile is to be a young unemployed woman, of indigenous culture, with disabilities, born in the southwest of the country, who has not lived in the United States, and resident in a large household, with few family members employed and female head of household with low level of education, in Playas de Rosarito.

Keywords: multidimensional poverty, ordered logit model, Baja California. 


\section{Introducción}

$\mathrm{S}$ egún las estimaciones de Coneval (2015) para 2014, en Baja California residían 105,500 personas en situación de pobreza multidimensional extrema, a los que se sumaban 879,400 en pobreza moderada. Estas cifras representaban, respectivamente, el 3.1\% y el $25.5 \%$ del total de habitantes del estado. En conjunto, $28.6 \%$ de los bajacalifornianos clasificaban como pobres, lo que supone una proporción relativamente reducida en comparación con otras entidades federativas del país. Sólo Nuevo León (20.4\%) y Distrito Federal (28.4\%) disfrutaban de cifras menores, mientras que el $46.2 \%$ de la población residente en México se encontraba en situación de pobreza multidimensional.

El estado de Baja California tiene otra particularidad importante. Es uno de los de mayor crecimiento demográfico de la federación. Entre 1990 y 2010, el número de residentes se elevó un 86.1\% (Conapo, 2014). Sólo Baja California Sur (91.4\%) y Quintana Roo (135.0\%) experimentaron crecimientos mayores. En el mismo periodo, la población del país apenas se expandió un $31.2 \%$.

El hecho de que Baja California sea un estado receptor de emigrantes, que éstos lleguen a la región en busca de empleo, con pocos recursos, que unos cuantos de ellos ni siquiera tengan como objetivo asentarse en la zona, sino cruzar a Estados Unidos, guarda relación con la población que se encuentra en situación de pobreza y da lugar a que ésta pueda presentar unas características particulares que no se observan en otras regiones del país. Los objetivos de este artículo son: describir las condiciones de vidas en las áreas de muy alto rezago social de cuatro de los cinco municipios de la entidad (Mexicali, Tecate, Tijuana y Playas de Rosarito), calcular las cifras de pobreza multidimensional de la población residente en esas zonas y analizar algunos de los factores sociodemográficos que explican esa situación.

Para ello, en primer lugar, se revisan los conceptos de marginación, rezago social y pobreza multidimensional; se presentan las principales características del censo realizado en 74 áreas geográfico estadísticas básicas (AGEB) y cuatro localidades de Baja California para obtener información sobre las condiciones de vida en las zonas de alto rezago social; y se introducen las técnicas econométricas que permiten analizar la relación entre condiciones sociodemográficas y pobreza. Posteriormente, se describen los resultados del censo en relación a las características de las viviendas y de los integrantes de los hogares, y se clasifica a los encuestados según las categorías de la pobreza multidimensional. En el tercer apartado, se muestran y discuten las estimaciones del modelo que indica los factores sociodemográficos que incrementan la probabilidad de clasificar en situación de pobreza extrema o moderada. Por último, se presentan las conclusiones del artículo.

\section{Conceptos, fuentes de datos y técnicas de análisis}

A mediados de la década de los noventa, el Consejo Nacional de Población (Conapo) concretó el diseño del índice de marginación (IM) aplicándolo al análisis de las entidades federativas y los municipios de México con datos del XI Censo General de Población y Vivienda (Conapo, 1994). Posteriormente, estos ejercicios se replicaron con datos de los censos de 2000 y 2010, de los conteos de 1995 y 2005, y de 
la encuesta intercensal de 2015 (Conapo, 2016). Asimismo, los análisis se ampliaron a los niveles de desagregación territorial de localidades y de AGEB urbanas (De la Vega, Téllez y López, 2012; Téllez, López y Romo, 2012).

A semejanza del IM, el Consejo Nacional de Evaluación de la Política de Desarrollo Social (Coneval) calcula el índice de rezago social (IRS), que "es una medida en la que un solo índice agrega variables de educación, de acceso a servicios de salud, de servicios básicos en la vivienda, de calidad y espacios en la misma, y de activos en el hogar" (Coneval, 2016). Específicamente, el IRS a nivel de AGEB se compone por 14 variables, que son los porcentajes de: población de 15 años y más con educación básica incompleta, población de 15 años o más analfabeta, población de 6 a 14 años que no asiste a la escuela, población de 15 a 24 años que no asiste a la escuela, población sin derechohabiencia a servicios de salud, personas que viven en hacinamiento, viviendas que no disponen de excusado o sanitario, viviendas que no disponen de drenaje, viviendas que no disponen de agua entubada de la red pública, viviendas que no disponen de energía eléctrica, viviendas con piso de tierra, viviendas que no disponen de lavadora, viviendas que no disponen de refrigerador, y viviendas que no disponen de teléfono fijo.

Tanto el IM como el IRS están asociados a unidades territoriales, ya sea estados, municipios, localidades o AGEB, a los que asignan un valor que permite clasificarlos en estratos de rezago o de marginación muy alto, alto, medio, bajo o muy bajo. La pobreza multidimensional, sin embargo, es un concepto que está vinculado a las personas (Bourguignon y Chakravarty, 2003). Son las personas las que se encuentran en situación de pobreza, no los territorios.

La pobreza multidimensional, que calcula Coneval (2015), combina el enfoque de líneas de pobreza con el de carencias sociales, de manera que clasifican en situación de pobreza multidimensional a las personas que cuentan con ingreso inferior a la Línea de Bienestar Económico (LBE) y además padecen al menos una carencia social. ${ }^{3}$ Las carencias sociales con las que se multi-dimensiona el tradicional concepto de línea de pobreza reflejan el acceso de la población a: 1) servicios de educación, 2) servicios de salud, 3) seguridad social, 4) calidad y espacios en la vivienda, 5) servicios básicos en la vivienda, y 6) alimentación. Como se observa en el Gráfico 1, la pobreza puede ser extrema o moderada. Clasifican en situación de pobreza extrema las personas que tienen un ingreso inferior a la Línea de Bienestar Económico Mínimo (LBEM) y padecen al menos tres de las seis carencias sociales. ${ }^{4} \mathrm{El} \mathrm{resto} \mathrm{de} \mathrm{pobres} \mathrm{clasifican} \mathrm{en} \mathrm{pobreza} \mathrm{moderada.}$

3- La LBE "permite identificar a la población que no cuenta con los recursos suficientes para adquirir los bienes y servicios que requiere para satisfacer sus necesidades (alimentarias y no alimentarias)” (DOF, 2010).

4- La LBEM "permite identificar a la población que, aun al hacer uso de todo su ingreso en la compra de alimentos, no podría adquirir lo indispensable para tener una nutrición adecuada” (DOF, 2010). 


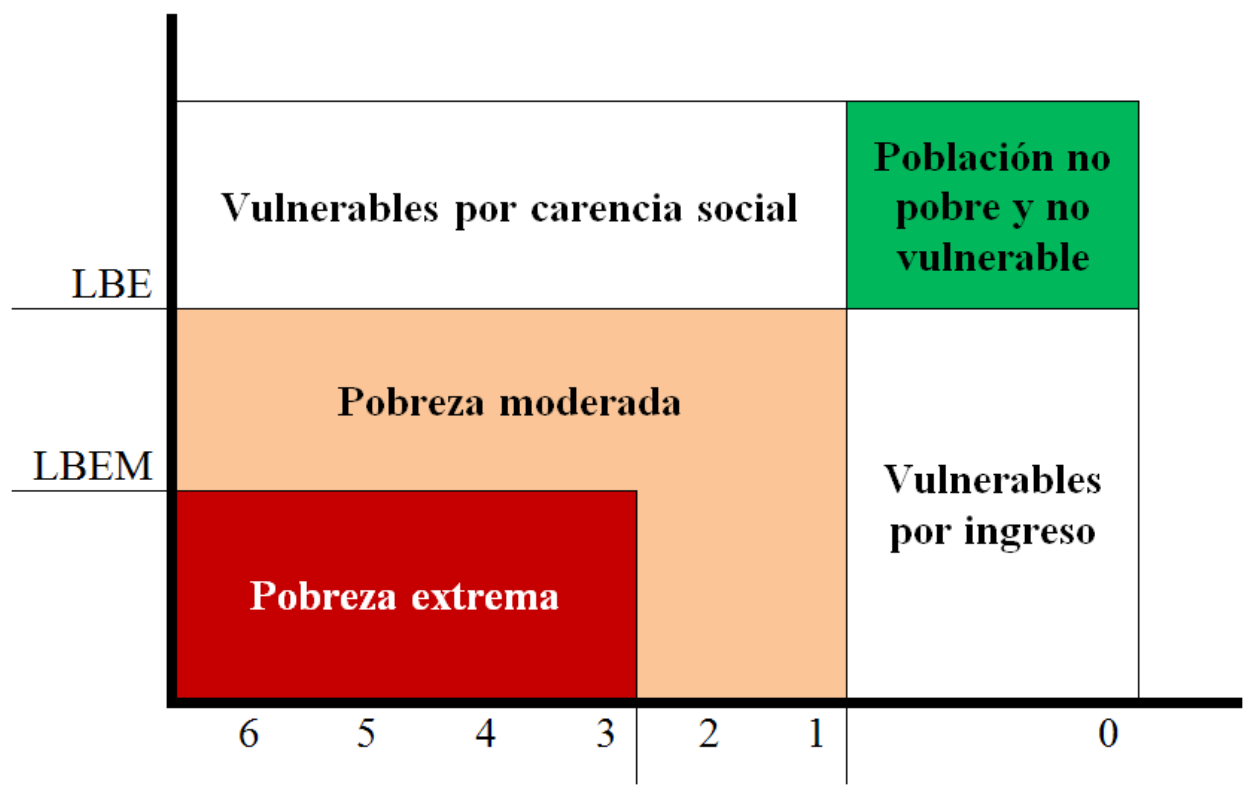

Carencias sociales

Fuente: Elaboración propia a partir de Coneval (2014: 42).

En esta investigación se utiliza información del proyecto Censo de hogares en zonas de muy alto rezago social de Baja California, 2014, que recabó datos en 74 AGEB y cuatro localidades rurales de los municipios de Mexicali, Tecate, Tijuana y Playas de Rosarito, caracterizadas por el rezago en términos de acceso a servicios de educación, salud, y disponibilidad de espacios, servicios y bienes en las viviendas. ${ }^{5}$ El Censo se llevó a cabo entre los meses de febrero y mayo de 2015, fue coordinado por los autores del presente artículo desde la sede de Tijuana de El Colegio de la Frontera Norte (El Colef) y contó con la participación de 37 entrevistadores, 6 supervisores y un analista de soporte técnico, para obtener registros de 11,844 viviendas, 11,955 hogares y 39,418 personas. La información recabada permite conocer las características del entorno, de las viviendas, así como de las carencias sociales, familiares e individuales de la población residente en las áreas de estudio. Asimismo, hace posible clasificar a cada habitante según los criterios y categorías de la pobreza multidimensional de Coneval, lo que permite la comparación directa de los resultados de la presente investigación con los publicados por este organismo.

5- Las cuatro localidades censadas fueron: Comunidad del Relleno Sanitario, El Nevado, Tres M (Pérez) y El Refugio. Las tres primeras pertenecen al municipio de Tijuana, mientras que la última se localiza en Playas de Rosarito. Sus códigos de identificación son: 1952, 1648, 1532 y 0249, respectivamente. Las AGEB censadas en el municipio de Mexicali fueron: 7228, 6925, 6910, 5946, 768A, 4219 y 5965 en la localidad de Mexicali;7622 y 7618 en Ciudad Morelos (Cuervos); 7637, 6304,6287 y 6319 en Progreso; 7789 en Puebla; 3032 en San Felipe; 558A, 6395, 6342, 7529 y 686A en Santa Isabel; y 6874 en Benito Juárez (Ejido Tecolotes). Las AGEB censadas en el municipio de Tecate fueron: 1692, 1616, 0942 y 1654 en la localidad de Tecate; 1508 en Nueva Colonia Hindú; y 1546 en Lomas de Santa Anita. En el municipio de Tijuana, se censaron las AGEB: $7947,2772,7951,6633,7970,7398,7383,7824,6934,2931,4726,7311,0136,2838,5160,5673,6614,2861,4641,6313,2857$, 7468 y 4410 de la localidad de Tijuana; 7754, 7523, 7487, 7519, 6737 y 621A en La Joya;8004 y 6883 en San Luis; 7612, 6239, 685A, 6012, 6027 y 6008 en Maclovio Rojas; y 6258, 6243, 607A y 6099 en Terrazas del Valle. En el municipio de Playas de Rosarito se censaron las AGEB:1131, 0256 y 0222 de la localidad de Playas de Rosarito; 1127 de Ampliación Ejido Plan Libertador; y 1108 y 0947 de Primo Tapia. 
En la siguiente sección se muestran los resultados descriptivos más relevantes en relación a estos aspectos y se calculan las cifras de pobreza multidimensional de las áreas censadas. Posteriormente, se analiza qué factores sociodemográficos hacen más probable que una persona clasifique como no pobre o en situación de pobreza moderada o de pobreza extrema. Para ello, se tiene en cuenta que la variable a explicar, $Y$, puede tomar tres valores que siguen una secuencia lógica desde la menor intensidad de la pobreza, identificando $y_{i}=0$ con "no pobre", $y_{i}=1$ con "pobre moderado", hasta la mayor intensidad: $y_{i}=2$, que se asocia a "pobre extremo". Dados estos tres valores, se definen dos umbrales, $\mu_{1}$ y $\mu_{2}$, a partir de los cuales la situación de cada individuo se asocia a cada uno de los posibles valores discretos de $Y$, tal que:

$$
\begin{array}{ll}
y_{i}=0 & \text { si } y_{i}^{*} \leq \mu_{1} \\
y_{i}=1 & \text { si } \mu_{1}<y_{i}^{*} \leq \mu_{2} \\
y_{i}=2 & \text { si } \mu_{2}<y_{i}^{*}
\end{array}
$$

A partir de estas acotaciones, y teniendo en cuenta que

$$
y_{i}^{*}=X_{i}{ }^{\prime} \beta+\varepsilon_{i}
$$

y que, por tanto,

$$
\varepsilon_{i}=y_{i}^{*}-X_{i}{ }^{\prime} \beta
$$

donde $X_{i}$ es la matriz de variables explicativas, $\beta$ es el vector de parámetros a estimar y $\varepsilon_{\mathrm{i}}$ son los errores de estimación; las probabilidades de cada opción, condicionadas por las características de $X_{i}$, se pueden obtener de la función de distribución del error evaluada en cada umbral:

$$
\begin{aligned}
& p\left(y_{i}=0 \mid X_{i}\right)=F\left(\mu_{1}-X_{i}^{\prime} \beta\right) \\
& p\left(y_{i}=1 \mid X_{i}\right)=F\left(\mu_{2}-X_{i}^{\prime} \beta\right)-F\left(\mu_{1}-X_{i}^{\prime} \beta\right) \\
& p\left(y_{i}=2 \mid X_{i}\right)=1-F\left(\mu_{2}-X_{i}^{\prime} \beta\right)
\end{aligned}
$$

Teniendo en cuenta los valores que toma la variable explicada, se procede a ajustar un modelo logit ordinal, de manera que $F(\cdot)$ adopta la forma de la función de distribución logística. Los parámetros $\beta_{j}$ y los umbrales, $\mu_{1}$ y $\mu_{2}$, se estiman mediante el método de la máxima verosimilitud bajo la restricción de que $\mu_{1}<\mu_{2}$, para garantizar que todas las probabilidades sean positivas.

Garza-Rodríguez (2016: 142) estima un modelo logístico dicotómico con el que analiza los factores que explican que un hogar clasifique como pobre o no pobre en los seis estados de México que comparten frontera con los Estados Unidos, mencionando que "no hay ninguna investigación actualmente que haya identificado y estimado los determinantes de la pobreza utilizando un análisis de regresión en esta región". A diferencia de ese estudio, el presente texto se refiere a un área mucho más específica, recurre a datos de un censo y no de una encuesta, analiza a individuos en vez de a hogares, y especifica grados de pobreza y no sólo si se es pobre o no pobre. A pesar de estas diferencias, Garza-Rodríguez (2016) aporta información sobre variables que pueden ser relevantes para explicar la situación que aquí se analiza. Lo 
mismo ocurre con los ensayos de Apata, Apata, Igbalajobi et al. (2010), Bogale y Korf (2009), Fissuh y Harris (2005), Geda, Jong, Kimenyi et al. (2005) y Marrugo-Arnedo, Del Risco-Serje, Marrugo-Arnedo et al. (2015). No están enfocados en el área geográfica de este artículo, pero utilizan técnicas similares y comprueban la relevancia de ciertos factores vinculados a la probabilidad de ser pobre.

A partir de la revisión de estas publicaciones, se consideró un conjunto de variables explicativas que se agrupan en tres grandes rubros: condiciones individuales, del hogar y de residencia. Dentro de las condiciones individuales, las variables que se contemplan para explicar la pobreza y su intensidad son: sexo, edad, parentesco con el jefe de hogar, cultura indígena, discapacidad e institución a la que se está afiliado para recibir servicios de salud. Entre las condiciones del hogar se incluyen: el número de personas que lo integran, el porcentaje de éstas que tiene empleo, y el sexo y nivel de escolaridad del jefe de hogar. Las variables que describen las condiciones de residencia son: municipio de residencia, número de años en su actual residencia, estado de nacimiento y el hecho de haber vivido alguna vez en los Estados Unidos. La definición, operacionalización, y los valores promedios y desviaciones estándar de estas variables se presentan en el Cuadro del Anexo.

Como se advierte, entre las variables explicativas de la pobreza multidimensional no se incluyen aquellas que ya están contenidas en la construcción de este tipo de pobreza como, por ejemplo, el ingreso, las características de las viviendas, el rezago educativo, o el acceso a la seguridad social. Asimismo, cabe destacar que con las variables elegidas apenas se pierden observaciones debido a la no respuesta de algunas preguntas por parte de los encuestados. Específicamente, se tiene información completa para 39,371 de las 39,418 personas censadas.

Según lo señalado en otras investigaciones, cabe esperar que el sexo afecte a la probabilidad de ser pobre. En concreto, que ésta sea mayor para las mujeres que para los hombres (González de la Rocha, 1986), por lo que el coeficiente correspondiente a esta variable debería presentar signo negativo: la probabilidad de ser pobre (extremo) aumenta cuando el valor de la variable se reduce de 1 (hombre) a 0 (mujer).

La edad también se presenta como una característica que puede resultar relevante. Debido al desarrollo del ciclo de vida, es de esperar que la probabilidad de clasificar como pobre se reduzca al aumentar la edad, en la medida que las personas van accediendo a puestos de trabajo mejor remunerados, disponen de mejores viviendas, etcétera. No obstante, llegado un punto, puede haber un deterioro de esta situación por motivos semejantes a los que postula la hipótesis del ciclo vital del ahorro (Fisher, 1930; Modigliani y Ando, 1957; Modigliani, 1986). Por ello, la variable edad $\left(E D A_{i}\right)$ se especifica en forma de polinomio cuadrático: $\beta_{j} E D A_{i}+\beta_{j+1} E D A_{i}^{2}$. A partir de lo argumentado, cabría esperar que el parámetro $\beta_{j}$ sea negativo (la probabilidad de ser pobre se reduce con la edad), pero que $\beta_{j+1}$ sea positivo (la probabilidad aumenta en las edades más avanzadas).

El parentesco que guarda cada uno de los integrantes del hogar con el jefe de familia también se presenta como una característica que puede ser determinante en la explicación de la pobreza. A diferencia de otros estudios, como los de Cortés (1997) y Garza-Rodríguez (2016), que recurren a datos de la Encuesta Nacional de Ingresos y Gastos de los Hogares (ENIGH) y calculan los determinantes de la pobreza a nivel de hogares, en este caso, al utilizar el concepto de pobreza multidimensional, no se clasifica como pobre a todo el hogar sino a cada uno de sus integrantes por separado. Si bien hay carencias compartidas por todos ellos, como la calidad y espacios de la vivienda o el acceso a la alimentación, otras carencias, como el rezago educativo, son específicas de cada individuo. Debido a ello, en un mismo hogar puede 
haber integrantes que clasifiquen en situación de pobreza multidimensional y otros no. Cabe esperar que el hecho de ser jefe de hogar, cónyuge, hijo/a o mantener otro parentesco arroje distintas propensiones a clasificar como pobre.

Debido a la relación directa que algunos autores encuentran entre pobreza y población indígena (CDI-PNUD, 2006; Peláez, 2012), cabe esperar que la estimación del parámetro asociado a esta variable presente signo positivo, indicando que la probabilidad de clasificar como pobre es mayor entre los residentes que se consideran indígenas de acuerdo a su cultura.

El signo del parámetro de la variable que indica si una persona tiene alguna discapacidad también se espera que sea positivo, mostrando una mayor propensión a clasificar como pobres entre aquellos residentes que padecen alguna limitación física o mental.

La institución a la que está afiliada cada persona para recibir servicios de salud aporta información sobre la calidad del trabajo que desempeña ella misma o alguno de sus familiares. Cabe esperar que la probabilidad de clasificar como pobres sea menor entre aquellos que están afiliados al Instituto Mexicano del Seguro Social (IMSS) o al Instituto de Seguridad y Servicios Sociales de los Trabajadores del Estado (ISSSTE), frente a los que disfrutan de cobertura del Seguro Popular; lo mismo que estos últimos en comparación con aquellos que no tienen derecho a servicio médico.

Respecto al número de personas en el hogar, existen hipótesis enfrentadas que argumentan, bien en el sentido de que la probabilidad de ser pobre aumenta con el tamaño de la familia, o bien que un mayor número de integrantes facilita la provisión de recursos y, por tanto, hace menos probable su pobreza (Cortés, 1997:132). Fissuh y Harris (2005), Garza-Rodríguez (2000 y 2016) y Marrugo-Arnedo et al. (2015) encuentran evidencia de que el tamaño de la familia correlaciona positivamente con la probabilidad de ser pobre. No obstante, también podría darse la situación contraria. Por ello, la variable número de personas en el hogar $\left(N U M P_{i}\right)$ se especifica en forma de polinomio cuadrático, $\beta N U M P_{i}+\beta_{j+1} N U M P_{i}^{2}$, esperando que la tendencia dominante sea la detectada por Garza-Rodríguez (2016) y, por tanto, la estimación de $\beta_{j}$ sea positiva, mientras que la de $\beta_{j+1}$ resulte con signo negativo.

El porcentaje de personas en el hogar que tienen empleo debe relacionarse con una menor probabilidad de clasificar en situación de pobreza a partir de que el trabajo reporta mayores ingresos. En ese caso, el parámetro de la variable presentará signo negativo.

El sexo del jefe de hogar también podría tener incidencia en la condición de pobreza de los integrantes de cada familia. Si bien Bogale y Korf (2009) y Garza-Rodríguez (2016) rechazan la hipótesis de que esta variable sea estadísticamente significativa para explicar la pobreza, Apata et al. (2010) encuentran que la probabilidad de permanecer en situación de pobreza es mayor en los hogares con jefatura femenina. De manera similar, Gang, Sen y Yun (2008) advierten mayor pobreza en los hogares liderados por mujeres. Al contrario, Marrugo-Arnedo et al. (2015) observan que, en su caso de estudio, un jefe de hogar mujer reduce la probabilidad de ser pobre, aunque el efecto es pequeño.

Fissuh y Harris (2005), Geda et al. (2005) y Marrugo-Arnero et al. (2015), entre otros, advierten que la educación del jefe de hogar es un factor fundamental para determinar la situación de pobreza. Al definir como categoría de referencia a los jefes de hogar con escolaridad inferior a primaria (Cuadro del Anexo), cabe esperar que los coeficientes de las tres variables dicotómicas asociadas a esta condición sean negativos y con mayor valor absoluto según se refieran a niveles educativos más altos.

Una vez controlada la incidencia de las demás variables incluidas en el modelo, es posible que haya 
municipios con condiciones que favorecen o dificultan el acceso a mejores viviendas, a servicios o a puestos de trabajo mejor remunerados. Aquellos donde la probabilidad de clasificar como pobre sea más alta tenderán a presentar signos positivos en sus coeficientes.

El número de años que una persona lleva residiendo en su actual hogar también puede aportar información relevante. En principio, cabe pensar que aquellos con más tiempo de residencia disponen de mejores condiciones de vivienda y de trabajo, así como de redes y de información que hacen más improbable que clasifiquen en situación de pobreza en comparación con los recién llegados.

El estado de nacimiento también se asocia a la condición de migrante. Aquellos nacidos en Baja California deberían estar mejor asentados, conocer mejor los mercados laborales y de la vivienda, etcétera, por lo que cabe esperar que tengan una menor probabilidad de clasificar como pobres que aquellos nacidos en otros estados del país. Asimismo, debe haber diferencias entre las regiones de procedencia. Como se verá más adelante, un porcentaje importante de las personas encuestadas nació en Sinaloa y Sonora; otro grupo numeroso proviene del suroeste del país: Chiapas, Oaxaca, Guerrero y Michoacán. No cabe esperar que la probabilidad de clasificar como pobre sea la misma en ambos grupos.

La última variable que se propone refleja el hecho de haber residido alguna vez en los Estados Unidos. Con su inclusión, se pretende comprobar el efecto que esta característica tiene sobre la pobreza en las áreas de estudio.

\section{Condiciones de vida de los residentes en zonas de alto rezago social}

Los resultados obtenidos a partir de la aplicación del cuestionario del Censo en las 74 AGEB urbanas y cuatro localidades rurales se agrupan en tres grandes ejes temáticos que describen las carencias sociales, familiares e individuales que padece la población residente en las áreas de estudio: 1) características de la vivienda, 2) características de los integrantes del hogar, y 3 ) cifras de pobreza multidimensional.

\subsection{Características de la vivienda}

Las familias encuestadas llevaban residiendo en su vivienda actual desde hacía una media de diez años. No obstante, la variabilidad de esta fecha fue bastante elevada. Había familias que residían en esa vivienda desde 1940. Otras recién acababan de llegar. La respuesta más habitual fue el año 2000 como el de inicio en su residencia actual, el cual se obtuvo en el 9.16\% de las entrevistas. Con una frecuencia mínimamente inferior, 9.15\%, mencionaron el año 2014 como el que llegaron a residir a esa vivienda.

Antes de trasladarse a su vivienda actual, $31 \%$ de las familias residían en la misma colonia, 53\% en la misma ciudad, $6 \%$ ya residían en el estado, $10 \%$ llegaron de otros estados del país, mientras que sólo el $1 \%$ llegó de otro país.

La vivienda era propiedad de los residentes en un $62 \%$ de los casos. De éstos, el $35 \%$ ya la había pagado totalmente, $22 \%$ aún la estaba pagando, y $43 \%$ se encontraba en otra situación. Entre el $38 \%$ de los residentes que no eran propietarios de la vivienda, $51 \%$ la rentaban, y a $49 \%$ les había sido prestada.

Las características de las viviendas que centraron la atención de la encuesta se agruparon en: 1) aque- 
llas relacionadas con los espacios (número de residentes, de cuartos, hacinamiento), 2) aquellas otras relacionadas con la calidad en la construcción del inmueble (material de paredes, techos, suelos), y 3 ) las relativas a los servicios básicos disponibles (electricidad, agua, drenaje, etcétera).

\subsubsection{Espacios en la vivienda}

En cuanto a los espacios, cabe mencionar que el promedio de residentes por vivienda fue de 3.33. El número máximo de residentes que se encontró en una vivienda fue 18. Sin embargo, lo más frecuente fueron las viviendas habitadas por tres personas, que llegaron a representar el $22 \%$ de las entrevistadas. Las siguientes más frecuentes fueron las de dos personas, $20 \%$, seguidas muy de cerca por las de cuatro personas, $20 \%$, y a mayor distancia por las unipersonales, $15 \%$, y las de cinco residentes, $13 \%$.

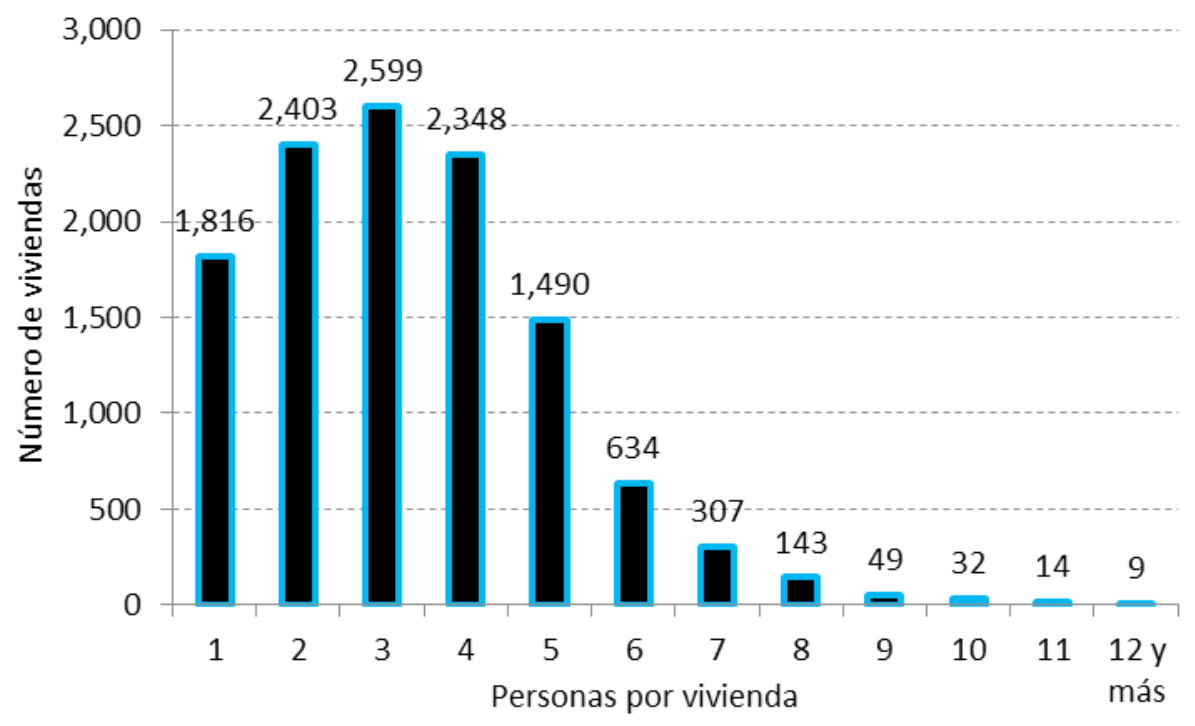

Fuente: Elaboración propia a partir del Censo de hogares en zonas de muy alto rezago social de Baja California, 2014.

Las viviendas contaban con una media de 1.66 cuartos usados para dormir. El número máximo de cuartos dormitorio fue 7 . Lo más frecuente es que sólo se utilizara un cuarto para dormir, $48 \%$ de los casos. En 39\% de las viviendas se usaban dos cuartos como dormitorio; tres en $10 \%$ y cuatro en $2 \%$.

Los residentes no contaban con un cuarto para cocinar en 23\% de las viviendas. Del 77\% que sí tenía cuarto para cocinar, $11 \%$ también lo usaba para dormir.

Sin contar pasillos ni baños, las viviendas encuestadas tenían 2.59 cuartos en promedio. El máximo de cuartos fue 12. El 17\% de las viviendas únicamente disponían de un cuarto. Lo más frecuente fueron las viviendas de tres cuartos, 33\%. Las de dos cuartos representaron el 32\% de los casos. Las de cuatro el 14\%.

Con los datos anteriores se comprobó que, en el 9\% de las viviendas, la razón de personas por cuarto era mayor de 2.5, lo que las clasifica en situación de hacinamiento. Entre los casos más preocupantes, 
destacan dos viviendas en las que se encontró a once residentes por cuarto. Otras dos viviendas tenían nueve residentes por cuarto; 17 viviendas con ocho personas por cuarto; $\mathrm{y} 26$ viviendas con siete.

\subsubsection{Calidad de la vivienda}

En cuanto a los materiales utilizados para la construcción de las viviendas cabe destacar que la mayor parte tenían paredes de madera, $61 \%$. El siguiente material más frecuente para las paredes fue el grupo de materiales más consistentes: tabique, ladrillo, block, piedra, cantera, cemento o concreto, $31 \%$. Mucho menos habitual fue encontrar viviendas con paredes de material de desecho, 6\%, no obstante, una cifra relevante por la condición que se está estudiando. En el 12\% de los casos se encontró que las paredes de la vivienda no eran independientes.

En su mayor parte, los techos eran de palma, tejamanil o madera, 68\%. A gran distancia se sitúa la losa de concreto, tabique, ladrillo o terrado con viguería como el segundo grupo de material más habitual, $19 \%$. Al igual que en el caso de las paredes, de nuevo en tercer lugar, aparece el material de desecho, 6\%. Mucho menos frecuentes, fueron la lámina de asbesto o metálica, 4\%, y la lámina de cartón, $2 \%$.

El material de la mayor parte del piso de la vivienda era cemento o firme en un $76 \%$ de los casos, tierra en $12 \%$, y madera, mosaico u otros recubrimientos en $11 \%$. El porcentaje de pisos de tierra se elevó hasta $20 \%$ al preguntar, no por la mayor parte de la vivienda, sino por alguno de los cuartos donde duermen o cocinan.

Teniendo en cuenta lo anterior, y que se considera como población en situación de carencia por calidad y espacios de la vivienda a las personas que residen en viviendas que presentan, al menos, una de las siguientes características:

- El material de los pisos de la vivienda es de tierra. (Lo cual ocurre en el $12 \%$ de las viviendas censadas)

- El material del techo de la vivienda es de lámina de cartón o desechos. (Lo que se observa en el $8 \%$ de los casos)

- El material de los muros de la vivienda es de embarro o bajareque; de carrizo, bambú o palma; de lámina de cartón, metálica o asbesto; o material de desecho. (Lo que afecta a $7 \%$ de las viviendas)

- La razón de personas por cuarto (hacinamiento) es mayor que 2.5. (Lo que se tiene en el $9 \%$ de las viviendas objeto de estudio)

Se obtuvo que $74 \%$ de las viviendas no presentaban ninguna de estas cuatro características, de manera que sus residentes no clasifican en situación de carencia por calidad y espacios en la vivienda. El 26\% restante mostraron al menos una de las características. En concreto, 17\% cumplían una característica, 7\% tenían dos, $2 \%$ tres, y apenas el $0.18 \%$ cumplían las cuatro de manera simultánea. El $26 \%$ de las viviendas con carencia por calidad y espacios, lleva a clasificar a un $28 \%$ de los residentes encuestados en situación de carencia por este concepto. 


\subsubsection{Servicios básicos en la vivienda}

En cuanto a disponibilidad de agua entubada, se encontró que 60\% de las viviendas tenían agua entubada en el interior de la vivienda, 19\% disfrutaban de agua entubada fuera de la vivienda pero dentro del terreno, 5\% tenían agua entubada de llave pública o hidrante, $2 \%$ agua entubada que acarreaban de otra vivienda, $13 \%$ tenían agua de pipa, y $1 \%$ agua de pozo, río, lago, arroyo u otra fuente. Destaca que únicamente el 79\% de los encuestados contaba con agua entubada al interior de su vivienda o terreno.

La mayor parte de las viviendas tenían drenaje conectado a la red pública, 57\%. La siguiente opción más frecuente a este respecto fue la de drenaje o desagüe de aguas sucias a fosa séptica, $26 \%$. Se encontró un $14 \%$ de viviendas sin drenaje. El resto tenía drenaje a una barranca, grieta, río, lago o mar.

De la situación del drenaje depende el tipo de baño o escusado de las viviendas. Así, se encontró que sólo $52 \%$ tenían escusado con conexión de agua, 29\% le echan agua, 3\% disponen de escusado sin admisión de agua (letrina seca o húmeda), 16\% tienen hoyo negro o pozo ciego, y $1 \%$ carece de baño o escusado de cualquier tipo. En el $6 \%$ de los casos, el baño o escusado era compartido con otra vivienda.

La basura de la vivienda la recogía un camión o carrito de basura en un 70\% de las ocasiones. La segunda opción más habitual respecto al tratamiento de basuras fue que la queman o la entierran, 23\%. En un $4 \%$ de los hogares la depositan en un contenedor o depósito. Mientras que el 1\% la tira en la calle o baldío; y otro $1 \%$ la tira en una barranca o grieta.

En el 70\% de las viviendas, la luz eléctrica provenía del servicio público, 1\% de una planta particular, $25 \%$ de otra fuente, y $4 \%$ carecían de luz eléctrica. Por otra parte, $62 \%$ de las viviendas censadas contaban con medidor de luz, mientras que $38 \%$ carecían de él. Esto da idea de la forma en que acceden a este servicio.

En cuanto al combustible usado para cocinar, se advirtió que en el 95\% de los hogares se recurría a gas de cilindro o tanque. A gran distancia, sólo un 3\% utilizaba leña o carbón. Mientras que el resto usaba electricidad, gas natural o de tubería u otros combustibles.

Con las características anteriores es posible determinar qué personas padecen carencia por falta de servicios básicos en la vivienda, que son aquéllas que residen en viviendas que presentan, al menos, una de las siguientes características:

- El agua se obtiene de un pozo, río, lago, arroyo, pipa; o bien, el agua entubada la obtienen por acarreo de otra vivienda, o de la llave pública o hidrante. (Esto ocurre en el $20 \%$ de las viviendas).

- No cuentan con servicio de drenaje, o el desagüe tiene conexión a una tubería que va a dar a un río, lago, mar, barranca o grieta. (Lo que se observa en el 16\% de las viviendas encuestadas).

- No disponen de energía eléctrica. (Lo que ocurre en el $4 \%$ de las viviendas).

- El combustible que se usa para cocinar o calentar los alimentos es leña o carbón sin chimenea. (Lo que afecta al 3\% de los hogares). 
A partir de los datos recopilados se advirtió que $68 \%$ de las viviendas no presentaban ninguna de estas cuatro características, de manera que sus residentes no clasifican en situación de carencia por servicios básicos en la vivienda. El 32\% restante mostraron al menos una de estas características. Específicamente, $24 \%$ tenían una característica, $6 \%$ tenían dos, $2 \%$ tres, y $1 \%$ cumplían las cuatro características de manera simultánea.

\subsection{Características de los integrantes del hogar}

La media de edad de los residentes en las áreas objeto de estudio se situó en 27 años. El 51\% eran hombres y el 49\% mujeres. Como se observa en el Gráfico 3, la mayor parte de la población tenía menos de 45 años de edad, en concreto, 82\%. La cohorte más numerosa es la de hombres de 5 a 9 años, esto es, población esencialmente joven. El 39\% de los censados aún no había cumplido los 20 años de edad.

\section{Gráfico 3. Distribución por edad y sexo de la población censada}

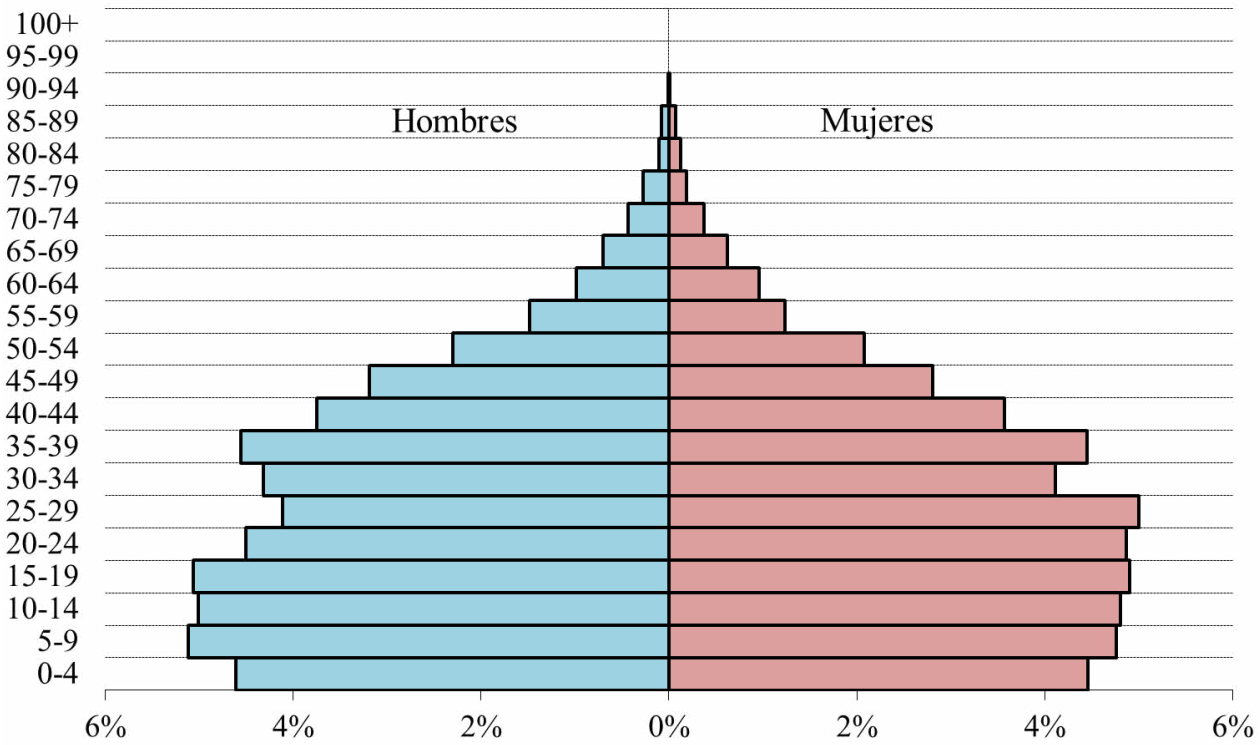

Fuente: Elaboración propia a partir del Censo de hogares en zonas de muyalto rezago social de Baja California, 2014.

El 40\% de la población de la que se obtuvo información eran hijos del jefe de hogar, 30\% eran jefes de hogar, y $20 \%$ cónyuges del jefe de hogar. El resto mantenía otro parentesco con el jefe del hogar donde residían. Entre los mayores de 12 años de edad, 35\% eran solteros, 29\% vivía en unión libre, 28\% estaban casados, $4 \%$ separados, $3 \%$ eran viudos y $1 \%$ divorciados.

Poco más de la mitad de la población de la que se tuvo conocimiento había nacido en Baja California, en concreto, $55 \%$ de los encuestados. Otros estados con alta representación como lugar de nacimiento fueron: Sinaloa 6\%, Chiapas 5\%, Michoacán 4\%, Jalisco 3\%, Guerrero 3\%, Nayarit 3\%, Oaxaca 2\%, Veracruz $2 \%$ y Sonora $2 \%$. El resto de entidades federativas se mencionaron en menos de $2 \%$ de las ocasiones. 
Las personas que siempre habían residido en el municipio representaron el 50\% del total. De los que habían residido en otros lugares, $18 \%$ se trasladaron hasta su municipio actual desde otro municipio de Baja California, 79\% se trasladaron desde otro estado del país, y 3\% desde los Estados Unidos.

\subsubsection{Acceso a servicios de salud}

Al consultar por la derechohabiencia a servicios de salud, se obtuvo que 34\% estaban afiliados al IMSS, $1 \%$ al ISSSTE, 38\% al Seguro Popular, y 25\% no tenía derecho a servicio médico. Estas personas, 25\%, que no contaban con adscripción o derecho a recibir servicios médicos de alguna institución que los presta, incluyendo el Seguro Popular, las instituciones públicas de seguridad social (IMSS, ISSSTE federal o estatal, Pemex, Ejército o Marina) o los servicios médicos privados, se consideraron en situación de carencia por acceso a los servicios de salud.

Apenas se detectaron casos de discapacidad. El 98\% de los encuestados no tenía limitación física o mental alguna; $0.7 \%$ padecía limitaciones para moverse, caminar, usar sus manos o brazos; $0.3 \%$ tenían alguna deficiencia o retraso mental; $0.3 \%$ padecía otras limitaciones físicas o mentales. Los casos de sordera o ceguera se situaron por debajo de $0.2 \%$ de la población censada.

\subsubsection{Lengua, cultura y acceso a servicios educativos}

También fueron muy pocos los casos de residentes que hablaran lengua indígena: sólo el $2.7 \%$ de los censados. De éstos, el $85 \%$ además hablaba español. Lo que deja un escaso $0.33 \%$ de los residentes que sólo habla lengua indígena. Al preguntar al total de la población si, de acuerdo con su cultura, se consideraban indígenas, sólo el 3.5\% respondió afirmativamente.

En cuanto a la condición de alfabetismo y el nivel de escolarización de los mayores de tres años de edad se tuvieron los siguientes datos. El 10\% de los residentes censados dijo no saber leer ni escribir un recado. El 8\% de la población mayor de tres años no tiene estudio alguno. No obstante, se encontró una proporción relativamente alta que aún estaba en proceso formativo. En concreto, 28\% de los encuestados todavía asiste a la escuela. Por cohortes de edad, $94 \%$ de los residentes de 6 a 11 años asistía a la escuela, siendo esta proporción de $88 \%$ en el grupo de 12 a 15 años y de $60 \%$ entre los que tienen de 16 a 18 años de edad. Las principales causas de abandono escolar fueron: que no alcanzó el dinero para mandarlo a la escuela, 39\% de los casos, y que decidió empezar a trabajar, 17\%. Entre los mayores de 15 años, el 6\% no tenía estudios, $32 \%$ había aprobado hasta primaria, $38 \%$ hasta secundaria, $20 \%$ preparatoria o bachillerato; $2 \%$ carrera técnica o comercial; $y$ otro $2 \%$ profesional.

Teniendo en cuenta que se considera con carencia por rezago educativo a la población que cumple alguno de los siguientes criterios:

- Tiene de tres a quince años, no cuenta con la educación básica obligatoria y no asiste a un centro de educación formal. (Lo que afecta al $4 \%$ de los residentes). 
- Nació antes de 1982 y no cuenta con el nivel de educación obligatoria vigente en el momento en que debía haberla cursado (primaria completa). (Lo cual implica al 3\% de la población objeto de estudio).

- Nació a partir de 1982 y no cuenta con el nivel de educación obligatoria (secundaria completa). (Característica que cumple el 7\% de los encuestados).

Se obtuvo que el 14\% de los residentes en las áreas censadas clasificaba en situación de carencia por rezago educativo.

\subsubsection{Situación laboral e ingresos}

En lo referente a la situación laboral de la población analizada con 15 años y más, se encontró que, en el último mes, $51 \%$ trabajó, a lo que se puede sumar $1 \%$ que tenía trabajo, pero no trabajó. La otra mitad de los encuestados se distribuyeron de la siguiente forma: 3\% buscó trabajo, 7\% eran estudiantes, $17 \%$ se dedicó a los quehaceres del hogar, $1 \%$ era jubilado o pensionado, $0.4 \%$ están incapacitados permanentemente para trabajar, y 20\% no trabajó ni realizó ninguna de las otras actividades mencionadas.

La ocupación principal de la población que estuvo trabajando durante el último mes fue la de obrero, $27 \%$. También resultaron frecuentes los casos de empleados del sector privado 14\%, trabajadores por cuenta propia 12\%, y albañiles $10 \%$. Con menor representación se encontraron residentes que habían trabajado como patrón o empleador de un negocio $6 \%$, jornalero o peón de campo 3\%, o empleado doméstico $3 \%$.

Se observó que los trabajos principales apenas ofrecían prestaciones a los encuestados. Sólo 22\% tenía derecho a recibir prestación por incapacidad por enfermedad, accidente o maternidad; $26 \%$ disfrutaba de Sistema de Ahorro para el Retiro (SAR) o Afore; $20 \%$ tenía derecho a crédito para vivienda, $12 \%$ a guardería, $30 \%$ a aguinaldo, $13 \%$ a seguro de vida. El 56\% de los encuestados, que tenían trabajo, no disfrutaban de derecho a ninguna de estas prestaciones.

De aquí, se pudo saber si cada persona padecía carencia de acceso a la seguridad social. Teniendo en cuenta los trabajadores que contaban entre sus prestaciones con servicios médicos y derecho a SAR o Afore, así como las personas de edad avanzada que estaban pensionadas, y los familiares de todos ellos, se observó que esta carencia podía llegar a afectar en torno a un 75\% de la población. Las bajas proporciones de pensionados, apenas un 18\% de los mayores de 60 años, y de trabajadores con derecho a prestaciones, unido a la mala calidad de los empleos, deja a la mayor parte de la población objeto de estudio al margen de la seguridad social.

Cifras semejantes se obtuvieron al preguntar por los servicios médicos relacionados con la actividad laboral. En el trabajo principal desarrollado durante el último mes, $60 \%$ de la población ocupada no tuvo derecho a servicio médico alguno. 34\% tuvo derecho a servicio médico en el IMSS, $1 \%$ en el ISSSTE, y el resto en otras instituciones.

Las remuneraciones mensuales que recibieron los trabajadores por su actividad principal abarcaron desde el máximo de $\$ 42,300$ hasta varios individuos que no recibieron remuneración alguna por el trabajo desarrollado. La retribución promedio fue de $\$ 3,882$. El pago más frecuente fue de $\$ 4,000$, muy cercano a la media, mostrando consistencia en la información recabada. Sólo en el 6\% de los casos se detectó que los residentes tuvieran ingresos por otras actividades, pensión, alquiler o renta de propiedades, 
programas sociales, becas, intereses bancarios, negocios, etcétera. En promedio, estas otras fuentes de ingresos reportaban $\$ 2,185$ mensuales.

Únicamente el 4\% de los encuestados había residido alguna vez en los Estados Unidos. Sin embargo, el 11\% tenía familiares viviendo en Estados Unidos. Aun así, sólo el 2\% de los hogares recibía remesas.

De manera semejante, prácticamente ninguno de los encuestados recibía apoyos de programas gubernamentales. El único programa con algún impacto era Oportunidades, que llegaba al 4.08\% de los hogares. Cerca del 1\% se situó el Programa de pensión para adultos mayores, beneficiando al 20\% de los residentes con 70 o más años. Otros programas por los que no se consultó y que resultaron tener alguna incidencia, aunque muy limitada, entre la población objeto de estudio fueron: Sin Hambre, Prospera, De la Mano Contigo, y 65 y Más. El conjunto de todos estos no llegaba más que al 2.45\% de los hogares.

Sumando todos los ingresos de todos los miembros del hogar, se encontraron familias que recibían mensualmente desde 0 hasta $\$ 62,500$. El ingreso promedio fue de $\$ 5,714$, con una desviación estándar de $\$ 3,736$, que indica la existencia de bastante variabilidad en los ingresos de unas familias a otras. No obstante, el índice de Gini para este conjunto de datos arrojó un valor de 0.319, mostrando un grado de concentración del ingreso no excesivamente alto si se compara con el habitual de regiones más heterogéneas, como la totalidad del país: 0.481 (PNUD, 2015:219). El ingreso más frecuente fue \$4,000, próximo al promedio.

Al dividir estos ingresos familiares entre el número de integrantes de cada hogar se obtuvo un ingreso mensual por persona que osciló entre la percepción de ningún ingreso hasta los \$16,500. El ingreso mensual promedio por persona de las áreas encuestadas fue de \$1,549, ligeramente por encima de la LBEM, que sólo incluye la canasta alimentaria, y que para marzo de 2015 Coneval sitúa en \$1,284, pero claramente por debajo de la LBE, que incluye las canastas alimentaria y no alimentaria, y que Coneval cifra en $\$ 2,628$ para las áreas urbanas. El ingreso mensual por persona más frecuente fue de $\$ 1,000$, nuevamente muy próximo al promedio. No obstante, la desviación estándar resultó relativamente elevada, \$1,158. El índice de Gini alcanzó un valor de 0.352 y, a modo de ejemplo, sirva decir que el 20\% de los residentes con menores ingresos sólo concentraba $6.6 \%$ del ingreso total, mientras que el $20 \%$ con mayores ingresos acumulaba el $42 \%$ del total.

A partir de estas cifras se pudo clasificar a cada persona en función de que su ingreso superara o no las líneas de bienestar calculadas por Coneval. Se encontró que el 50\% de las personas censadas tenía un ingreso mensual inferior a la LBEM, lo que ni siquiera les sería suficiente para adquirir la canasta alimentaria. Al considerar también la canasta no alimentaria, se encontró que el $87 \%$ de los residentes en las zonas de estudio tenía ingresos inferiores a la LBE, clasificando fuera del bienestar económico.

\subsubsection{Acceso a la alimentación}

A pesar de esta escasez de ingresos, los datos no mostraron la existencia de graves carencias en la alimentación. Tan solo 1\% de los hogares realizaba una comida al día, 35\% realizaban dos comidas y 63\% llegaban a las tres comidas diarias. Los niños no acostumbraban a desayunar únicamente en un $6 \%$ de los hogares. Además, de éstos, el $27 \%$ desayunaba en la escuela, de manera que el porcentaje de niños que no desayunaba se limita al $4 \%$.

Las mayores deficiencias con la alimentación se detectaron en cuanto a la variedad de los alimentos. La dieta fue muy poco variada para el $37 \%$ de los hogares. Un $28 \%$ de las familias también detectó 
escasez de alimentos en algún momento durante los últimos tres meses. En total, 25\% de los hogares encuestados clasificaron en situación de carencia de acceso a la alimentación.

\subsection{Cifras de pobreza multidimensional}

A partir de la información anterior y atendiendo a la metodología de Coneval que permite calcular las cifras de pobreza multidimensional en función de que cada persona disponga de un ingreso inferior a la línea de bienestar, así como un cierto número de carencias sociales, se asoció a cada encuestado con alguna de las categorías consecuentes. Como se muestra en el Cuadro 1 y en el Gráfico 4, únicamente 2.67\% de los encuestados clasificó como población no pobre y no vulnerable. Se tuvo que $8.99 \%$ eran vulnerables por ingreso y $10.19 \%$ vulnerables por carencias sociales. El grueso de la población presentó las características propias de la pobreza moderada: $56.83 \%$. Finalmente, se detectó que $21.32 \%$ de los entrevistados se encontraba en pobreza extrema, esto es, disponían de un ingreso inferior al necesario para adquirir la canasta alimentaria y además padecían al menos tres carencias sociales.

\section{Cuadro 1. Medición de la pobreza multidimensional en las áreas de estudio}

\begin{tabular}{|ccc}
\hline & Número de personas & Porcentaje \\
\hline Población censada & 39,418 & $100 \%$ \\
\hline Pobreza: & & \\
\hline Población en situación de pobreza & 30,804 & $78.15 \%$ \\
\hline Población en situación de pobreza moderada & 22,402 & $56.83 \%$ \\
Población en situación de pobreza extrema & 8,402 & $21.32 \%$ \\
\hline Población vulnerable por carencias sociales & 4,018 & $10.19 \%$ \\
\hline Población vulnerable por ingresos & 3,543 & $8.99 \%$ \\
\hline Población no pobre y no vulnerable & 1,053 & $2.67 \%$ \\
\hline Privación social: & & \\
\hline Población con al menos una carencia social & 34,822 & $88.34 \%$ \\
\hline Población con al menos tres carencias sociales & 13,148 & $33.36 \%$ \\
\hline Indicadores de carencia social: & & \\
Rezago educativo & 5,646 & $14.32 \%$ \\
\hline Carencia por acceso a los servicios de salud & 9,709 & $25.00 \%$ \\
\hline Carencia por acceso a la seguridad social & 29,485 & $74.80 \%$ \\
\hline Carencia por calidad y espacios en la vivienda & 10,917 & $27.70 \%$ \\
Carencia de servicios básicos en la vivienda & 12,537 & $31.81 \%$ \\
Carencia por acceso a la alimentación & 10,921 & $27.71 \%$ \\
\hline Bienestar: & & \\
\hline Población con ingreso inferior a la LBEM & 19,837 & $50.32 \%$ \\
Población con ingreso inferior a la LBE & 34,347 & $87.14 \%$ \\
\hline
\end{tabular}

Fuente: Elaboración propia a partir del Censo de hogares en zonas de muy alto rezago social de Baja California, 2014. 
Gráfico 4. Clasificación de la población residente en el área de estudio según categorías de pobreza multidimensional

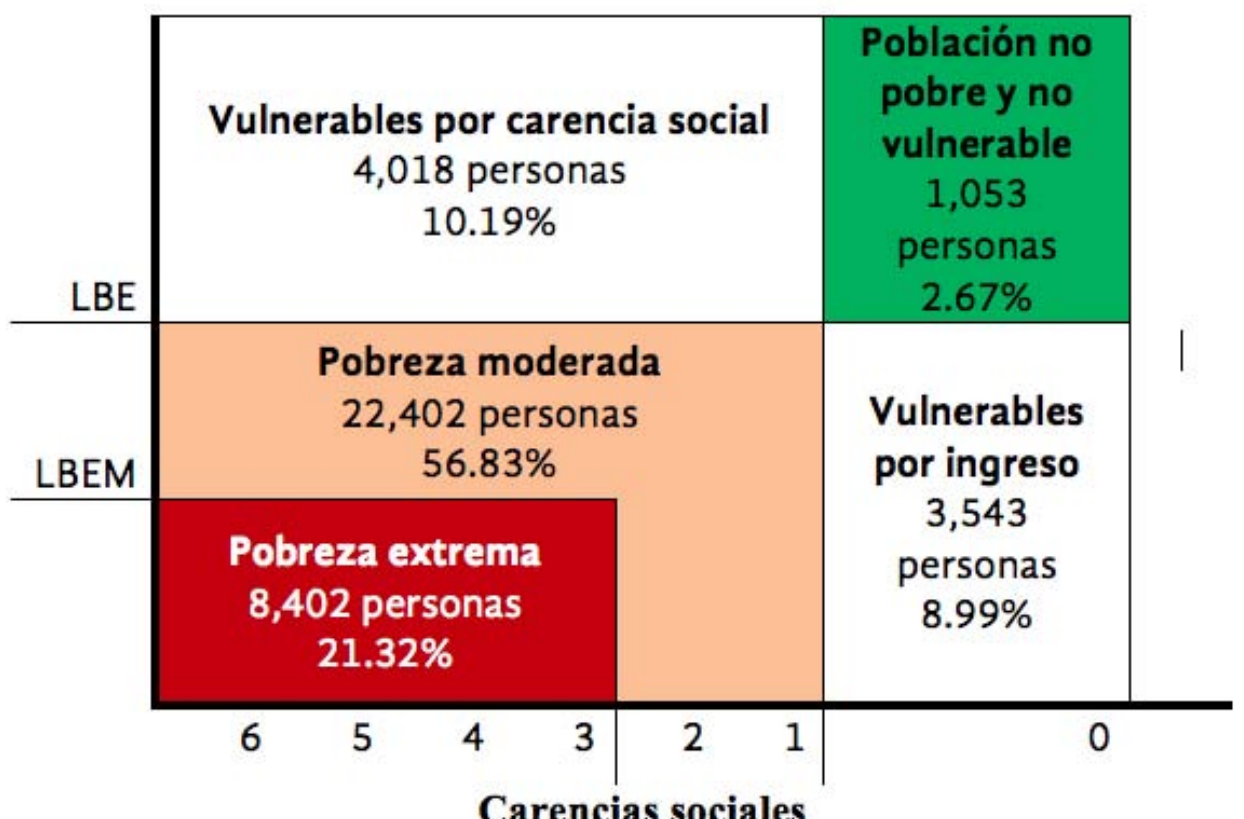

Fuente: Elaboración propia a partir del Censo de hogares en zonas de muy alto rezago social de Baja California, 2014.

Estas cifras de pobreza son muy superiores a las que presenta Coneval (2015) para todo Baja California. No en vano, se encuestó a la población de las zonas con mayor rezago del estado. Cabe recordar que la pobreza extrema sólo afecta al 3.06\% de los baja californianos, mientras que en esta muestra de 39,418 personas se eleva hasta el 21.32\%. Los no pobres y no vulnerables, que en Baja California son el 26.51\%, aquí apenas llegan al 2.67\%.

\section{Factores explicativos de la pobreza multidimensional}

El Cuadro 2 contiene las estimaciones del modelo logit ordinal que explica la probabilidad de no ser pobre $\left(y_{i}=0\right)$, ser pobre moderado $\left(y_{i}=1\right)$ o pobre extremo $\left(y_{i}=2\right)$ en función de diferentes características de los individuos, como su sexo, edad, o parentesco con el jefe de hogar, entre otras. Como se observa, la gran mayoría de las variables incluidas en el modelo son significativas al $99 \%$ de confianza. Las únicas excepciones son: la variable que se refiere a los nacidos en Sinaloa o Sonora, que es significativa al 95\% de confianza, así como el parentesco de hijo/a y el sexo de cada persona, cuyos valores son estadísticamente nulos. La significatividad conjunta del modelo se puede verificar mediante el contraste de razón de verosimilitudes. El estadístico correspondiente, igual a 21,864.8, resulta muy superior al valor crítico de la chi-cuadrado con 26 grados de libertad (45.64), lo que lleva a rechazar la hipótesis de que las variables independientes no explican la probabilidad de ser pobre. 
- Revista de Ciencias Sociales y Humanidades. ISSN-P: 0188-9834 ISSN-E: 2395-8669.

Cuadro 2. Estimaciones del modelo logit ordinal para

la probabilidad de clasificar en situación de pobreza

\begin{tabular}{|c|c|c|c|}
\hline Variable & Coeficiente & Error estándar & \\
\hline Sexo (masculino) & -0.0044 & 0.0234 & \\
\hline Edad & -0.0469 & 0.0025 & $* * *$ \\
\hline Edad2 & 0.0004 & 0.0000 & $* * *$ \\
\hline \multicolumn{4}{|l|}{ Parentesco: } \\
\hline Jefe de hogar & 0.4179 & 0.0473 & $* * *$ \\
\hline Cónyuge & 0.4714 & 0.0493 & $* * *$ \\
\hline $\mathrm{Hijo/a}$ & -0.0332 & 0.0400 & \\
\hline Cultura indígena & 0.3257 & 0.0592 & $* * *$ \\
\hline Discapacidad & 0.3675 & 0.0874 & $* * *$ \\
\hline \multicolumn{4}{|l|}{ Servicios de salud: } \\
\hline IMSS o ISSSTE & -1.8806 & 0.0303 & $* * *$ \\
\hline Seguro Popular & -0.7101 & 0.0273 & $* * *$ \\
\hline Otro seguro & -1.3702 & 0.1353 & $* * *$ \\
\hline Número de personas en el hogar & 0.5062 & 0.0249 & $* * *$ \\
\hline Número de personas en el hogar2 & -0.0281 & 0.0024 & $* * *$ \\
\hline Tasa de empleo & -3.2242 & 0.0539 & $* * *$ \\
\hline Sexo del jefe de hogar & -0.3771 & 0.0250 & $* * *$ \\
\hline \multicolumn{4}{|l|}{ Escolaridad del jefe de hogar: } \\
\hline Primaria & -0.5091 & 0.0465 & $* * *$ \\
\hline Secundaria & -0.9330 & 0.0478 & $* * *$ \\
\hline Más de secundaria & -1.2765 & 0.0519 & $* * *$ \\
\hline \multicolumn{4}{|l|}{ Municipio de residencia: } \\
\hline Mexicali & -0.9589 & 0.0675 & $* * *$ \\
\hline Tecate & -0.2100 & 0.0776 & $* * *$ \\
\hline Tijuana & -1.0808 & 0.0570 & $* * *$ \\
\hline Años en su actual residencia & -0.0002 & 0.0002 & \\
\hline
\end{tabular}




\begin{tabular}{|c|c|c|c|c|}
\hline \multicolumn{2}{|c|}{ Estado de nacimiento: } & & & \\
\hline \multicolumn{2}{|c|}{ Baja California } & -0.3759 & 0.0298 & *** \\
\hline \multicolumn{2}{|c|}{ Sinaloa o Sonora } & -0.0991 & 0.0430 & ** \\
\hline \multicolumn{2}{|c|}{ Chiapas, Oaxaca, Guerrero o Michoacán } & 0.1483 & 0.0363 & **** \\
\hline \multicolumn{2}{|c|}{ Residió en EUA } & -0.1730 & 0.0606 & $* * *$ \\
\hline \multicolumn{2}{|c|}{ Umbral 1: $\mu 1$} & -5.2054 & 0.1148 & $* * *$ \\
\hline \multicolumn{2}{|c|}{ Umbral $2: \mu 2$} & -1.6363 & 0.1111 & $* * *$ \\
\hline \multicolumn{2}{|c|}{ Log-verosimilitud } & $-30,811.4$ & & \\
\hline \multicolumn{2}{|c|}{$\begin{array}{l}\text { Estadístico de contraste de razón de verosimilitudes: chi-cuadra- } \\
\qquad \mathrm{do}(26)\end{array}$} & $21,864.8$ & & $* * *$ \\
\hline \multirow[t]{3}{*}{ Pseudo R-cuadrado: } & Cox y Snell & 0.330 & & \\
\hline & Nagelkerke & 0.384 & & \\
\hline & McFadden & 0.204 & & \\
\hline
\end{tabular}

Fuente: Elaboración propia a partir del Censo de hogares en zonas de muy alto rezago social de Baja California, 2014.

Nota: ${ }^{\star * \star}$ indica que la estimación es significativa al 99\% de confianza; ${ }^{\star *}$ el nivel de confianza es $95 \%$.

Los umbrales, $\mu_{1}$ y $\mu_{2}$, a partir de los que se asocia a cada individuo el correspondiente valor discreto de $Y$, también son plenamente significativos. Esto indica que los datos utilizados permiten distinguir con claridad cada una de las tres categorías especificadas: no pobre $\left(y_{i}=0\right)$, pobre moderado $\left(y_{i}=1\right)$ y pobre extremo $\left(y_{i}=2\right)$.

Respecto a las estimaciones de los parámetros, se encuentra que el referido al sexo de cada individuo no es significativo. Sin embargo, el sexo del jefe de hogar sí lo es. Dado que el signo del coeficiente es negativo, los integrantes de hogares con jefatura femenina son más propensos a clasificar como pobres extremos una vez descontado el efecto de las demás características. Para ahondar en el conocimiento de esta situación, se procedió a reestimar el modelo utilizando la misma especificación, sólo que excluyendo la variable relativa al sexo del jefe de hogar. Al proceder de esta forma, se obtuvo que el sexo de cada individuo empezaba a ser una variable relevante para explicar la intensidad de la pobreza. El resto de coeficientes apenas modificaba su valor, al tiempo que conservaban su signo y significatividad. De ello se desprende que el sexo es una variable determinante para explicar la pobreza multidimensional en el área de estudio, pero que es más relevante el sexo del jefe de hogar que el de cada individuo, ya que, al tener en cuenta ambos, el primero tiende a anular la incidencia del segundo.

Para la edad se obtiene una estimación negativa en el término lineal y positiva en el cuadrático. Ello indica que la probabilidad de ser pobre se reduce al aumentar la edad, concretamente hasta los 57 años, para luego empezar a aumentar. Jóvenes y ancianos son los grupos más propensos a padecer pobreza multidimensional. 
El parentesco con el jefe de hogar también resulta ser una característica relevante. Una vez que se controla por las demás variables, se tiene el resultado, tal vez inesperado, de que la probabilidad de clasificar como pobre es mayor para el jefe de familia y su cónyuge que para el resto de integrantes del hogar. Para el hijo/a no hay evidencia suficiente de que su condición incremente su probabilidad de clasificar como pobre, apenas distinguiéndose del resto de miembros del hogar (padre o madre, hermano/a, nieto/a, suegro/a, etc.), que actúan como categoría de referencia.

En el caso de estimar el modelo sólo con las variables de parentesco (Cuadro 3), se obtienen unos resultados más apegados a lo que sería una primera intuición. El signo de los coeficientes es negativo, en vez de positivo, indicando que el jefe de hogar es menos propenso a clasificar como pobre multidimensional, seguido por su cónyuge. De nuevo, no hay diferencias significativas entre el hijo/a y el resto de integrantes del hogar. No obstante, el Cuadro 2, en comparación con el Cuadro 3, muestra que, una vez descontados los efectos de las demás variables que se incluyen en el modelo completo (sexo, edad, etc.), la relación entre ser jefe de hogar (o su cónyuge) y la probabilidad de ser pobre se invierte. A igualdad de edad, tamaño de hogar, municipio de residencia, etcétera, el jefe de hogar y su cónyuge son los más propensos de la familia a clasificar como pobres.

Cuadro 3. Estimaciones del modelo logit ordinal para la probabilidad de clasificar en situación de pobreza: sólo parentesco

\begin{tabular}{|c|c|c|c|c|}
\hline \multicolumn{2}{|c|}{ Variable } & Coeficiente & Error estándar & \\
\hline \multicolumn{5}{|c|}{ Parentesco: } \\
\hline \multicolumn{2}{|c|}{ Jefe de hogar } & -0.6099 & 0.0367 & $* * *$ \\
\hline \multicolumn{2}{|c|}{ Cónyuge } & -0.4045 & 0.0386 & $* * *$ \\
\hline \multicolumn{2}{|c|}{ Hijo/a } & -0.0145 & 0.0353 & \\
\hline \multicolumn{2}{|c|}{ Umbral 1: $\mu 1$} & -1.5633 & 0.0330 & $* * *$ \\
\hline \multicolumn{2}{|c|}{ Umbral $2: \mu 2$} & 1.0575 & 0.0323 & $* * *$ \\
\hline \multicolumn{2}{|c|}{ Log-verosimilitud } & $-38,378.82$ & & \\
\hline \multicolumn{2}{|c|}{$\begin{array}{l}\text { Estadístico de contraste de razón de verosimilitudes: chi- } \\
\qquad \text { cuadrado(3) }\end{array}$} & $6,829.26$ & & $* * *$ \\
\hline \multirow[t]{3}{*}{ Pseudo R-cuadrado: } & Cox y Snell & 0.018 & & \\
\hline & Nagelkerke & 0.021 & & \\
\hline & McFadden & 0.009 & & \\
\hline
\end{tabular}

Fuente: Elaboración propia a partir del Censo de hogares en zonas de muy alto rezago social de Baja California, 2014.

Nota: ${ }^{* * *}$ indica que la estimación es significativa al 99\% de confianza.

El Cuadro 2 también muestra que la probabilidad de que una persona sea pobre extremo es mayor entre aquellos que se consideran indígenas de acuerdo con su cultura, lo cual afecta al $3.52 \%$ de los encuestados. Algo parecido, incluso con un poco más de intensidad, se tiene para aquellos que padecen alguna limitación física o mental, y que son el 1.53\% de la muestra.

La institución a la que las personas están afiliadas para recibir servicios de salud también guarda relación con la probabilidad de ser pobre y con la intensidad de esa característica. La menor propensión a la pobreza se encuentra entre los afiliados al IMSS o al ISSSTE. Le siguen otros seguros (de instituciones 
públicas y seguros privados) y los inscritos en el Seguro Popular. La mayor probabilidad de encontrarse en situación de pobreza se tiene entre los que carecen de derecho a servicio médico, que es la categoría de referencia. Entendiendo que los trabajos formales están más vinculados al IMSS, por ejemplo, y que los informales se corresponden con el Seguro Popular o la ausencia de seguro, se obtiene la relación habitual entre informalidad y pobreza.

El número de personas por hogar muestra la tendencia esperada. La probabilidad de clasificar como pobre extremo aumenta con el número de integrantes hasta un punto en el que empieza a reducirse. En concreto, la probabilidad aumenta rápidamente desde los hogares unipersonales hasta los de cuatro miembros, para luego seguir expandiéndose, pero con menor intensidad, hasta el máximo de hogares de 9 miembros. A partir de ahí, la probabilidad de ser pobre se reduce. No obstante, cabe tener en cuenta que no se encontraron hogares con más de 12 integrantes, por lo que la subtendencia a la reducción de la probabilidad resulta bastante limitada.

La tasa de empleo del hogar se relaciona de manera inversa con la probabilidad de ser pobre. Cuanto mayor es la proporción de empleados de un hogar, menor es la probabilidad de que cualquiera de los miembros de ese hogar clasifique como pobre.

El nivel educativo del jefe de hogar también se relaciona de manera inversa con la pobreza. Los coeficientes estimados son todos negativos y van creciendo en valor absoluto con el nivel de escolaridad del jefe de hogar.

Respecto al municipio de residencia, se observa que los coeficientes de Mexicali, Tecate y Tijuana son negativos, lo que indica que la mayor propensión a clasificar como pobre se tiene en Playas de Rosarito (categoría de referencia). La probabilidad más baja es para los residentes en Tijuana, seguidos de Mexicali y, a mayor distancia, Tecate. Los dos municipios con menor tamaño de su núcleo urbano (Tecate y Playas de Rosarito) son los que más se asocian con la pobreza.

La variable que mide los años que lleva cada persona viviendo en su actual residencia, si bien presenta el signo negativo que cabía esperar, no resulta significativa. Por tanto, no hay evidencia de que el tiempo de permanencia en el lugar sea un factor determinante de la condición e intensidad de la pobreza.

La región de origen, sin embargo, sí es relevante. El hecho de haber nacido en Baja California se corresponde con una menor probabilidad de clasificar como pobre extremo. Los procedentes de Sinaloa y Sonora también presentan una probabilidad inferior al resto de entidades federativas, no obstante, mucho más semejante a los otros estados que los oriundos de Baja California. Las personas nacidas en el suroeste del país (Chiapas, Oaxaca, Guerrero y Michoacán) son los que tienen mayor probabilidad de ser pobres extremos.

Finalmente, se encuentra que aquellas personas que alguna vez han residido en los Estados Unidos son menos propensas a clasificar como pobres.

\section{Conclusiones}

A partir de la encuesta aplicada en zonas de muy alto rezago social de los municipios de Mexicali, Tecate, Tijuana y Playas de Rosarito, se obtuvo información sobre las condiciones de vida de 39,418 residentes. Esto permitió calcular las cifras de pobreza multidimensional siguiendo la técnica de Cone- 
val (2014). Se encontró que $56.83 \%$ de los encuestados clasificaba en situación de pobreza moderada y $21.32 \%$ en pobreza extrema. De las seis carencias sociales, la que afectó a un mayor número de personas fue la de acceso a la seguridad social. El 74.80\% de los encuestados padecía esta situación. Lo mismo ocurre en toda Baja California a partir de los datos de Coneval (2015): la carencia más extendida es la de acceso a la seguridad social, que afecta a un 51.8\% de los baja californianos. La siguiente carencia con mayor impacto en el área de estudio fue la de servicios básicos en la vivienda, detectada en el $31.81 \%$ de los encuestados.

Además de las carencias, los bajos ingresos de la población resultaron clave en la determinación de la pobreza. Hasta el $87.14 \%$ de los residentes en las áreas de estudio clasificó por debajo de la LBE. El $50.32 \%$ ni siquiera disponía de ingresos suficientes para adquirir la canasta alimentaria. En este sentido es muy importante destacar la mínima incidencia que los apoyos gubernamentales estaban teniendo en las zonas analizadas.

En relación con las características sociodemográficas que se asocian a una mayor probabilidad de clasificar en situación de pobreza multidimensional, se encontró que la gran mayoría de los factores planteados resultan significativos. El perfil más propenso a padecer pobreza extrema es el de una joven, desempleada, de cultura indígena, con alguna discapacidad, nacida en el suroeste del país, que no ha vivido en Estados Unidos y que reside en un hogar numeroso, del municipio de Playas de Rosarito, con pocos familiares empleados y jefatura femenina con bajo nivel de estudios.

Conocido este perfil, que apunta hacia los grupos vulnerables tradicionales, aunque con ciertos matices, debería ser posible implementar políticas mucho más específicas en beneficio de la población que se encuentra en situación de pobreza. No obstante, a la vista de que en la actualidad la amplia variedad de programas ya existentes tiene una incidencia mínima entre la población necesitada, no parece que el problema sea tanto el diseño y la especificidad o generalidad de los mismos, como la insuficiencia de recursos y la falta de identificación de beneficiarios para que estas acciones alcancen a las personas que más las requieren.

Las características particulares de la pobreza en Baja California parece que se limitan a la menor presencia de la misma en comparación con otras regiones del país y a la concentración de los afectados en focos muy específicos que se localizan en las zonas de expansión de los núcleos urbanos y cerca de los pasos fronterizos, pero esto apenas influye en el perfil de los pobres. Los factores sociodemográficos que caracterizan a la población que clasifica en situación de pobreza multidimensional, que es precisamente lo que se analiza en este artículo, son prácticamente idénticos a los reportados por otras investigaciones para regiones y países distintos. No se encontró evidencia concluyente de que un mayor tiempo de residencia se asociara con una menor probabilidad de pobreza, a pesar de tratarse de un área receptora de migrantes. Sí se encontró que la región de origen de estos migrantes afecta a sus condiciones de vida, lo mismo que haber residido alguna vez en los Estados Unidos. Futuras investigaciones han de centrarse en el análisis de las redes sociales extra-familiares de los residentes en estas áreas, algo que quedó al margen del presente estudio y que ayudaría a complementar la información aportada por las características individuales y de los hogares. 


\section{Referencias}

Apata, Temidayo, O. Apata, O. Igbalajobi y SamuelAwoniyi. 2010. Determinants of rural poverty in Nigeria: evidence from small holder farmers in South-western, Nigeria. Journal of Science and Technology Education Research, 1(4): 85-91.

Bogale, Ayalneh y Benedikt Korf. 2009. Analysis of poverty and its covariates among smallholder farmers in the eastern Hararghe highlands of Ethiopia. Ponencia presentada en International Association of Agricultural Economists Conference, Beijing.

Bourguignon, François y Satya Chakravarty. 2013. The measurement of multidimensional poverty. Journal of Economic Inequality, 1(1): 25-49. https://doi.org/10.1023/A:1023913831342

CDI-PNUD. 2006.Informe sobre desarrollo humano de los pueblos indígenas de México 2006. México: Comisión Nacional para el Desarrollo de los Pueblos Indígenas y Programa de las Naciones Unidas para el Desarrollo.

Conapo. 1994.Desigualdad regional y marginación municipal en México, 1990. México: Consejo Nacional de Población y Comisión Nacional del Agua.

Conapo. 2014. Indicadores demográficos básicos. México en cifras. http://www.conapo.gob.mx/es/CONAPO/Indicadores_sociodemograficos. (13 de noviembre de 2015).

Conapo. 2016. Índice de marginación por municipio 1990-2015.Datos abiertos del índice de marginación. http:// www.conapo.gob.mx /es / CONAPO / Datos_abiertos_del_índice_de_marginación. (15 de julio de 2016).

Coneval. 2014. Metodología para la medición multidimensional de la pobreza en México. México: Consejo Nacional de Evaluación de la Política de Desarrollo Social.

Coneval. 2015. Anexo estadístico de pobreza en México: anexo estadístico 2014. Medición de la pobreza. http://www.coneval.org.mx/Medicion/MP/Paginas/AE_pobreza_2014.aspx. (9 de noviembre de 2016). Coneval. 2016. Índice de rezago social 2015 a nivel nacional, estatal y municipal. Medición de la pobreza. http://www.coneval.org.mx/Medicion/IRS/Paginas/Indice_Rezago_Social_2015.aspx. (29 de junio de 2016)

Cortés, Fernando. 1997. Determinantes de la pobreza de los hogares. México, 1992. Revista Mexicana de Sociología, 59 (2): 131-160. https://doi.org/10.2307/3541165

De la Vega, Sergio, Yolanda Téllez y Jorge López. 2012.Índice de marginación por localidad 2010. México: Consejo Nacional de Población.

DOF. 2010. Lineamientos y criterios generales para la definición, identificación y medición de la pobreza. Diario Oficial de la Federación (16 de junio 2010).

Fisher, Irving. 1930.The theory of interest as determined by impatience to spend income and opportunity to invest it. Nueva York: The Macmillan Company.

Fissuh, Eyob y Mark Harris. 2005. Modeling determinants of poverty in Eritrea: a new approach. http:// repec.org/esAUSM04/up.26810.1088476172.pdf. (20 de enero de 2017)

Gang, Ira, KunalSen $\quad$ y $\quad$ Myeong-SuYun. $2008 . \quad$ Pover- 
ty in rural India: caste and tribe. Review of Income and Wealth, 54 (1): 50-70. https://doi.org/10.1111/j.1475-4991.2007.00259.x

Garza-Rodríguez, Jorge. 2000. The determinants of poverty in Mexico: 1996. Tesis de doctorado, Columbia: University of Missouri-Columbia.

Garza-Rodríguez, Jorge. 2016. Los determinantes de la pobreza en los estados mexicanos en la frontera con Estados Unidos. Estudios Fronterizos, 17 (33):141-167.

Geda, Alemayehu, Niek de Jong, Mwangi Kimenyi y Germano Mwabu. 2005. Determinants of poverty in Kenya: a household level analysis. University of Connecticut Department of Economics Working Paper Series, 2005-44.

González de la Rocha, Mercedes. 1986. Los recursos de la pobreza: familias de bajos ingresos de Guadalajara. Guadalajara: El Colegio de Jalisco-CIESAS.

Marrugo-Arnedo, Carlos, Katherin Paola Del Risco-Serje, Verena del Carmen Marrugo-Arnedo, Jorge Antonio Herrera-Llamas y Gerson Javier Pérez-Valbuena. 2015. Determinantes de la pobreza en la región Caribe colombiana. Revista de Economía del Caribe, 15: 47-69. https://doi.org/10.14482/ecoca.15.7192 Modigliani, Franco. 1986. Life cycle, individual thrift and the wealth of nations. The American Economic Review, 76(3): 297-313.https://doi.org/10.1126/science.234.4777.704

Modigliani, Franco y Albert Ando. 1957. Test of the life cycle hypothesis of saving. Bulletin of the Oxford University Institute of Economics \& Statistics, 19(2):99-124. https://doi.org/10.1111/j.1468-0084.1957.mp19002002.x

Peláez, Óscar. 2012. Análisis de los indicadores de desarrollo humano, marginación, rezago social y pobreza en los municipios de Chiapas a partir de una perspectiva demográfica. Economía, Sociedad y Territorio, 12 (38):181-213.

PNUD. 2015. Informe sobre desarrollo humano 2015: trabajo al servicio del desarrollo humano. Nueva York: Programa de las Naciones Unidas para el Desarrollo.

Téllez, Yolanda, Jorge López y Raúl Romo. 2012. Índice de marginación urbana 2010.México: Consejo Nacional de Población. 


\section{Anexo}

Cuadro A. Definición de las variables y estadísticas descriptivas

\begin{tabular}{|c|c|c|c|}
\hline Variable & Descripción & Promedio & $\begin{array}{l}\text { Desviación } \\
\text { estándar }\end{array}$ \\
\hline \multicolumn{4}{|c|}{ Condiciones individuales: } \\
\hline Sexo & 1 si es hombre, 0 si es mujer. & 0.5062 & 0.5000 \\
\hline Edad & Años cumplidos. & 27.2385 & 17.8184 \\
\hline \multicolumn{4}{|l|}{ Parentesco: } \\
\hline Jefe de hogar & 1 si es el jefe de hogar, 0 en otro caso. & 0.3033 & 0.4597 \\
\hline Cónyuge & 1 si es el cónyuge del jefe de hogar, 0 en otro caso. & 0.2007 & 0.4005 \\
\hline Hijo/a & 1 si es el hijo o hija del jefe de hogar, 0 en otro caso. & 0.4009 & 0.4901 \\
\hline \multicolumn{4}{|c|}{$\begin{array}{c}\text { El resto de integrantes del hogar (padre o madre, hermano/a, nieto/a, sobrino/a, etc.) fungen como categoría de } \\
\text { referencia. }\end{array}$} \\
\hline Cultura indígena & 1 si se considera indígena, 0 en otro caso. & 0.0334 & 0.1798 \\
\hline Discapacidad & $\begin{array}{l}1 \text { si tiene alguna limitación física o mental, } 0 \text { en otro } \\
\text { caso. }\end{array}$ & 0.0153 & 0.1229 \\
\hline \multicolumn{4}{|l|}{ Servicios de salud: } \\
\hline IMSS o ISSSTE & 1 si está afiliado al IMSS o al ISSSTE, 0 en otro caso. & 0.3491 & 0.4767 \\
\hline Seguro Popular & 1 si está inscrito en el Seguro Popular, 0 en otro caso. & 0.3833 & 0.4862 \\
\hline Otro seguro & $\begin{array}{l}1 \text { si está afiliado a otra institución pública distinta de } \\
\text { las anteriores o disfruta de seguro privado, } 0 \text { en otro } \\
\text { caso. }\end{array}$ & 0.0067 & 0.0817 \\
\hline \multicolumn{4}{|c|}{ Aquellos que no están afiliados o inscritos para recibir servicios de salud actúan como categoría de referencia. } \\
\hline Tamaño & Número de personas en el hogar. & 4.1642 & 1.7805 \\
\hline Tasa de empleo & Porcentaje de personas en el hogar con empleo. & 0.3686 & 0.2406 \\
\hline Sexo del jefe de hogar & 1 si es hombre, 0 si es mujer. & 0.7327 & 0.4425 \\
\hline \multicolumn{4}{|c|}{ Escolaridad del jefe de hogar: } \\
\hline Primaria & 1 si ha cursado hasta primaria, 0 en otro caso. & 0.3852 & 0.4866 \\
\hline Secundaria & 1 si ha cursado hasta secundaria, 0 en otro caso. & 0.3740 & 0.4839 \\
\hline Más de secundaria & 1 si ha cursado más de secundaria, 0 en otro caso. & 0.1772 & 0.3819 \\
\hline \multicolumn{4}{|c|}{ Los jefes de hogar con nivel de escolaridad menor a primaria son la categoría de referencia. } \\
\hline \multicolumn{4}{|c|}{\begin{tabular}{|l|l|} 
Condiciones de residencia: & \\
\end{tabular}} \\
\hline \multicolumn{4}{|c|}{ Municipio de residencia: } \\
\hline Mexicali & 1 si reside en Mexicali, 0 en otro caso. & 0.0753 & 0.2639 \\
\hline Tecate & 1 si reside en Tecate, 0 en otro caso. & 0.0390 & 0.1935 \\
\hline Tijuana & 1 si reside en Tijuana, 0 en otro caso. & 0.8491 & 0.3580 \\
\hline \multicolumn{4}{|c|}{ Los residentes en Playas de Rosarito son la categoría de referencia. } \\
\hline Tiempo de residencia & Número de años en su residencia actual. & 12.7021 & 54.2290 \\
\hline & Estado de nacimiento: & & \\
\hline
\end{tabular}


- Revista de Ciencias Sociales y Humanidades. ISSN-P: 0188-9834 ISSN-E: 2395-8669.

\begin{tabular}{|c|c|c|c|}
\hline Baja California & 1 si nació en Baja California, 0 en otro caso. & 0.5509 & 0.4974 \\
\hline Sinaloa o Sonora & 1 si nació en Sinaloa o Sonora, 0 en otro caso. & 0.0824 & 0.2750 \\
\hline Suroeste & 1 si nació en Chiapas, Oaxaca, Guerrero o Mi- \\
choacán, 0 en otro caso. & 0.1386 & 0.3455 \\
\hline \multicolumn{3}{|c|}{ Las demás entidades federativas sirven de categoría de referencia. } \\
\hline Residió en EUA & 1 si alguna vez vivió en Estados Unidos, 0 en otro \\
caso. & 0.0338 & 0.1808 \\
\hline
\end{tabular}

Fuente: Elaboración propia a partir del Censo de hogares en zonas de muy alto rezago social de Baja California, 2014. 